\title{
Status of the Quality-of-Life Index and its Related Factors in the Women of Rasht: A Population-Based Study
}

\section{Asiyeh Namazi ( $\square$ anamazi55@yahoo.com )}

University of Social Welfare and Rehabilitation Sciences

Hassan Rafiey

University of Social Welfare and Rehabilitation Sciences

Mirtaher Mousavi

University of Social Welfare and Rehabilitation Sciences

Ameneh Setareh Forouzan

University of Social Welfare and Rehabilitation Sciences

Gholamreza Ghaedamini Harouni

University of Social Welfare and Rehabilitation Sciences

\section{Research Article}

Keywords: Quality of Life, life satisfaction, Quality of Life Index, women

Posted Date: September 29th, 2021

DOI: https://doi.org/10.21203/rs.3.rs-847629/v1

License: (c) (i) This work is licensed under a Creative Commons Attribution 4.0 International License. Read Full License 


\section{Status of the quality-of-life index and its related factors in the women of Rasht: a population- based study}

Asiyeh Namazi* ${ }^{1}$, Hassan Rafiey ${ }^{2}$, Mirtaher Mousavi ${ }^{3}$, Ameneh Setareh Forouzan ${ }^{3}$, Gholamreza Ghaedamini Harouni ${ }^{3}$

1- PhD candidate in Health and Social Welfare, University of Social Welfare and Rehabilitation Sciences, Tehran, Iran anamazi55@yahoo.com

2- Department of social welfare management, Tehran University of Social Welfare and Rehabilitation Sciences, Iran.

3- social welfare management Research Center, University of Social Welfare and Rehabilitation Sciences, Tehran, Iran 


\begin{abstract}
Background: Quality of Life is a key element in social policy so that its placement on the agenda of community development has a constructive and positive effect on the life and performance of the individual and society. This study was designed to assess the status of a quality-of-life index and some related factors in the public population of women in Rasht, which is the capital city of Guilan Province, Iran.

Methods: This cross-sectional study was performed on 800 women in Rasht who were selected by cluster random sampling. The data collection tool was the Ferrans and Powers Quality of Life questionnaire, which has two parts: Satisfaction and Importance with life. Each section consists of four subscales: Health and performance, Social and economic, Psychological/spiritual, and Family. Its scoring is done on the Likert scale. Data analysis was done using descriptive statistics and one-way analysis of variance, independent $t$-test and regression.

Results: The mean score (SD) of the quality-of-life index in this study was 21.39(4.10), which was higher than the mean level and showed a relatively good condition. There was a statistically significant difference between the mean score of quality-of-life index in terms of education level, but within age groups, this difference was not significant. Correlation tests showed no statistically significant relationship between duration of the marriage, age of marriage and age of spouse with the women's quality-of-life score of ( $p>0.05)$.

Conclusions: Although the quality of life of the women studied was above average, appropriate interventions should be designed to maintain and improve it, because the feeling of satisfaction increases the ability to cope with problems and mental pressures and improves the level of mental and physical health of couples and ultimately of all members of society.
\end{abstract}

Keywords: Quality of Life, life satisfaction, Quality of Life Index, women 


\section{Introduction}

The desire to have a high quality and desirable life always exists in people(1)and is one of the main research activities to assess the public health of people(2). The purpose of contemporary societies focuses on the physical, psychological and social well-being of the population, translated as a set of policies and actions aimed at contributing effort for the repair of Quality of Life and assessment of the concept(3). The concept of Quality of Life is considered an interdisciplinary and dynamic concept that changes over time(4)and many different definitions have been proposed(5)(6)(7).

The World Health Organization defines Quality of life as: "Quality of life is determined by a person's individual perception of their position in life, in the cultural context and value systems in which they live and concerning their goals, expectations, relationships and needs"(8).Despite the fact that some experts have defined Quality of Life as life satisfaction, others see it as the degree of satisfaction with the possibilities of that life. Life satisfaction is considered as how much of the desired goal that can be achieved on the basis of the best possible performance of an individual(9).

There is a growing appreciation that life satisfaction is one of the most important aspects of a person's quality of life. Since satisfaction varies from person to person, it is important to use appropriate measurement tools that can identify the differences between them. It should also be emphasized that the sum of satisfaction scores alone does not accurately reflect the quality of life(10). Ferrans defines the Quality of Life as: "Quality of life means a person's sense of well-being that originates in their satisfaction or dissatisfaction of life aspects that are important to him/her.", In other words, Quality of life reflects the living conditions and well-being of individuals and shows a person's satisfaction with health, education, employment, living and social environment, relationships and security(10)(11).Frain and colleagues (2008) considers the quality of life as a person's perception of their position in life according to their culturalvalue context(12).As all human efforts are focused on improving the quality of life and achieving complete satisfaction, this is considered to be the most fundamental problem in the development of societies, and it is, therefore, necessary to identify problems that may affect the quality of life. Women are considered not only as one of the objectives of any development of society but also as an effective lever to achieve the objectives of economic and social development (13). Most experts also agree that the concept of Quality of Life has different physical, social, psychological, and economic dimensions(14). Ferrans considers four identical dimensions: "health and functioning", "social-economic", psychological/spiritual and "family", including the child, husband and family health. Many scientists believe that happiness and satisfaction are the two main characteristics of quality of life and these domains can be considered to influence these characteristics(15).

Women have a central role in family in any culture, and their mental, physical and social wellbeing is closely connected to society's overall well-being(16). Today, the reduction of gender inequalities, which is an integral part of the process of development of society, has resulted in significant changes in the employment status and, in general, has changed women's social status. However, in developing countries, gender disparity is rampant compared to the developed countries(17).

The researchers say that since quality of life is a subjective thing, the most appropriate way to research quality of life is to ask people directly about their perception of their life. Besides that, some experts suggest that the measure of the quality of life in the domain of satisfaction and general happiness, which is only definable by the individual, can only be measured by the use 
of surveys of individuals (18). Although a variety of studies purport to assess quality of life, there is remarkably little agreement about the underlying concepts or theoretical framework that the measures represent. several studies have been conducted in Iran to assess this concept, most of them use the health-related Quality of Life Questionnaire or the World Health Organization Quality of Life Questionnaire, which only examines the physical and mental health dimensions. But many social elements affect the quality of life of individuals (13) (14) (15) (16) (17).In this study, we used the Quality of Life index questionnaire to survey the quality of life of healthy people, and also consider the social aspects of quality of life(19).The advantages of this questionnaire are in having subjects related to satisfaction with important aspects in life, fluency and family focus, which seemed not to be considered in the previous quality-of-life questionnaires used in Iran. On this basis, the present study was carried out with the aim of answering the question of "What is the state of the quality-of-life index in the public female population of Rasht?"

In addition, the following hypotheses are proposed:

There is a difference in the quality of life between women interviewed according to their age group.

There is a difference in the quality of life between women questioned according to their level of education.

There is a difference in the average quality of life of the women surveyed based on their employment status and the type of occupation (public or private).

\section{Method and materials Study characteristics}

The present study was a population-based cross-sectional survey that was conducted in the first half of 2020 in the city of Rasht (a city in the north of Iran). Rasht is the most populated and the biggest city in the Guilan province with an estimated total female population of 478,293inhabitants in 2017. The population of women in urban areas was estimated to be 377,978 . The sample consisted of women aged 30-65 years. Inclusion criteria were; at the time of the survey, having lived in Rasht city for at least one-year, married women who consented to participate in this study, having the ability to communicate verbally to answer the questions, those who were physically and mentally healthy at the time of the research and did not use any medication for a particular disease. In addition, the exclusion criteria included women who had a family member who suffered from a chronic debilitating disease, an incurable disease or congenital anomalies, the person or their first-degree family infected with the coronavirus (COVID-19) in the last few months; those who have recently lost their family head for various reasons; (death, divorce, etc.), women who have a history of domestic violence in the past few months or who are currently exposed to domestic violence.

\section{Sampling process}

Considering that no previous study has been conducted to measure the quality-of-life index in the general population of Iranian women, the sample size was estimated using the Krejcie and Morgan Table. According to this table, for a population of more than 100,000, the sample number would be 384. It must be calculated to determine the optimal size of each cluster and the number of design effects. In this study, the design efficiency was considered to be equal to 2. The sample size should be determined based on the relationship Ncs $=$ Nsrs $\times$ Deffcs. In this context, Nsrs is the calculated sample size for simple random sampling and Ncs is the actual sample size for cluster sampling with a design effect equal to Deffcs. which means that the 
cluster sampling method requires twice the initial sample size. Therefore, the total required sample count is 768 people. In total, 800 respondents were included in this study. Respondents who did not answer the satisfaction or importance questions $(n=16)$, were excluded. After applying these exclusion criteria, 784 respondents were included in the present study. The cluster random sampling method was used due to the dispersion of the statistical population, and the sample was selected corresponding to the population size from each area. Rasht city, in terms of division, is divided into five metropolitan areas. This includes two developed and developing regions and one less developed area such that each of these areas was considered as a cluster. In each cluster, the sampling was initiated by randomly selecting several alleys in the desired urban area and referring to the residential location within that area. The point of origin of the block of clusters started from the right inside each cluster and the completion of the relevant questionnaire from them. When the required number of women and eligible individuals was not obtained by referring to all the families of the main block, sampling of the adjacent alley to the right of the main alley in the same area was performed to complete the required number of participants. After selecting a woman matched to the study inclusion criteria, the trained interviewer provided a description of the study and the requirements for participation and then administered the study protocol.

\section{Variable measurement}

The data collection tool consisted of two questionnaires. In the first, 10 questions focused on characteristics such as age, age at marriage, duration of the marriage, occupation status, level of education in participant and her husband, number of children, average monthly income, place of birth and the place of residence. The instrument used to measure the quality of life was Quality of Life Index (QLI) Questionnaire which was developed by Ferrans and Powers(20). This scale is built on a conceptual psychometric model and proven in numerous international studies, based on precise methodological methods, and includes a representation of the constructs it aims to measure.

In addition, it is designed in a simple way that prevents participants from getting bored, especially when people are disabled for reasons such as old age or low level of education (21).It has its origins in English, but has been translated into 20 languages around the world, including Persian. The current general version of the Ferrans and Powers' Quality of Life Index consists of 33 items for each of the two sections of satisfaction and importance. The subjects assign scores in both sections with values ranging from 1 to 6 . In the first part, the scale varies from very dissatisfied (1) to very satisfied (6). In the second part, the range of points differs from the lowest score of (1) for the option "It does not matter" up to score 6 for "it is very important". Each of the two sections above includes four dimensions (subscales): Health/functioning (13 items), psychological/spiritual (7 items), social and economic (8 items), and family (5 items) (19). It should be noted that points 21 (employed) and 22 (unemployed) of the socio-economic dimensions are mutually exclusive; this means that only one of them should be considered. To determine scores, each satisfaction factor is compared with its equivalent in importance. The values are the combined raw scores of the two parts obtained after standardization. It should be noted that there are no reverse points and cut-off points in this structure. Scores for this questionnaire are calculated both in terms of quality of life as a whole and separately in each of the four domains, and the post-standardization score range is between 0 and 30 . The higher the calculated score for a woman, the better the quality of life she has.(19). This questionnaire is suitable for both self-administration and interview. In self-report mode, it takes about 10 minutes to complete, and no special training is required. 
Overall, the findings of a previous study in Iran showed that the Persian version of this questionnaire is a suitable tool for measuring the Quality-of-Life index. The reliability coefficient was reported for subscales from 0.74 to 0.90 ,indicating a good reliability(19)

In this study, the reliability of the questionnaires was re-examined because the population studied was different. In this way, the questionnaire was administered to 30 women in the target group, and the same questionnaire was given to them a month later. The result of ICC was 0.87 for the first part of the questionnaire and 0.78 for the second part. In addition, the Cronbach's alpha reliability coefficient for them was between 0.80 and 0.88 , indicating a high reliability.

\section{Statistical analyses}

Descriptive statistical methods (frequency distribution table, mean, standard deviation) were used to describe the population studied. The hypothesis of normality of the distribution of variables was investigated by the Kolmogorov-Smirnov test. The total score of QLI and its four domains assessed in the study were considered as dependent variables. Independent t-tests (in bivariate data) and ANOVA test (in multivariate data) were employed to determine the impact of socio-demographic factors on QLI. Pearson's correlation (two-tailed) shows the relation between QOL domains, and quantitative variables, and forward LR Logistic Regression reveals multiple association between socio-demographic factors and QLI. All statistical analyses were conducted using a statistics package for social sciences (SPSS software, version 23.0, Chicago, Il), and p-values $<0.05$ were considered statistically significant.

\section{Results}

\section{Participant's characteristics}

The aim of this study was to examine the state of the quality-of-life index and some related factors in Rasht women. We conducted interviews and collected information for all of the 800 eligible women enrolled in the study.

Based on the demographic data; The mean age (SD) of women was 42.01 (9.27) years. The most common age range was30-39 years $(47.4 \%)$. In terms of education level, most of them $(60.3 \%)$ were in the bachelor's degree or higher group. The mean (SD) age of marriage was $24.30(5.40)$ years, and the mean duration of marriage (SD) was 17.33(11.12) years. The majority of the women $(73.5 \%)$ were born in the urban area. Moreover, the mean (SD) age of the spouse reported 45/73 (10/51) years. The mean (SD) of number of children was 1.59 (1.09) (median: 2). Most of the women were housewives, but $21.40 \%$ were employed. The majority of the subjects' husbands had education in a bachelor's degree $(55.7 \%)$. Also, the majority of respondents had a monthly income at an average level. (34.4\%).

\section{Women's QLI and domain scores}

The mean (SD) score for the standard Quality of Life Index was 21.39 (4.10), indicating a relatively good situation. The scores obtained from the subscales of this index are presented separately in Table 1. As shown in the results of this table, the highest average score was given to the "family dimension"23.47 (4.95) and the worst score to the "socioeconomic subscale"19.94(3.99).

\section{Factors related to QLI}

Table 2 depicts the scores of QOL questionnaire at different socio-demographic characteristics. The quality-of-life index status by age and education level was examined using a one-way variance test. Overall, there was a significant difference between the mean score of the qualityof-life index in the education groups $(\mathrm{F}=3.29, \mathrm{P}=0.03)$. Therefore, this hypothesis that "there is a statistical difference between the mean Quality of Life among the surveyed women based on their education level" was confirmed. But there was no statistically significant difference 
between the average Quality of Life Index obtained and the age groups $(F=0.79, P=0.49)$. In addition, the results of Tukey's post hoc test showed that all age groups formed a homogeneous group with each other, and that the other hypothesis of the study, "that there is a significance difference between the mean Quality of Life of the women surveyed according to their age groups", was not confirmed.

The state of women's Quality of Life Index in this study was examined by a t-test of two independent samples, in two groups of employees and housewives' samples. The test results showed that there was no statistically significant difference between the mean score of qualityof-life index of employed women $(\mathrm{M}=21.40)$ and of women who were housewives $(\mathrm{M}=$ $21.45)(\mathrm{T}=0.15, \mathrm{df}=782, \mathrm{P}=0.87)$. Homogeneity of variance (Levene's Test) was established in the two groups $(\mathrm{P}=21.45)$. The quality of life of the employees, and also a function of their types of jobs, were evaluated (public or private). The results of the independent $t$ tests showed that there was no statistically significant difference between the two in terms of the mean Quality of Life Index ( $\mathrm{T}=-1.67$, df $=526, \mathrm{P}=0.09$ ). Therefore, the third hypothesis of the study was not sustained either. (There was no difference between the women's mean quality of life in the survey based on their employment status and type of occupation.

Other results showed that there was not a statistically significance between the average Quality of Life Index to women heads of household compared to men head of household ( $\mathrm{T}=-0.37$, df $=782, \mathrm{P}=0.70)$. The results of the Pearson correlation test have a positive and direct statistical correlation between job satisfaction of employed persons and the index of their quality of life $(\mathrm{P}=0.001, \mathrm{r}=0.49)$, indicating the quality of life of people increases with job satisfaction.

Further results obtained from Pearson's correlation test suggest that no statistically significant correlation was observed between the variables 'age of marriage' $(\mathrm{P}=0.20, \mathrm{r}=0.04)$, 'duration of marriage' ( $\mathrm{P}=0.14, \mathrm{r}=-0.05)$, 'age of husband' $(\mathrm{P}=0.35, \mathrm{r}=-0.03)$, and 'number of offspring' $(\mathrm{P}=0.32, \mathrm{r}=-0.03)$ with the quality-of-life index of women.

The results of regression analysis in the present study showed that none of the predictor variables explained the quality-of-life index (Table 3).

\section{Discussion}

The construct of Quality of Life is considered as an analytical structure and a key element in policy-making and review of public policies which is an important element of individuals' well-being and is referred to as an indicator of social development. It is therefore important to determine overall QoL and its related factors, especially among women. This study started from a simple correlation analysis to see if there are any significant associations between the variables of demographics and the score of QoL index. Of course, correlations can only tell us that there is an association between the variables, but they cannot unveil what kind of relationship it is, and whether or not there is any causality in such associations.

As mentioned previously, rarely in Iranian studies has the quality-of-life status of healthy women being studied using the general version of the Quality-of-Life Index questionnaire which examines importance and satisfaction in various aspects of life. Other existing questionnaires used both inside or outside the country, more from a health perspective, focus on the quality of life of people, whereas Ferrans and Powers' questionnaire shows us a profound and more comprehensive situation of people in terms of quality of life.

The results of this study (21 out of 30) showed that the mean women's Quality of Life in Rasht was above average. The results of Mirzaei et al.'s study on married women in Tabriz showed that the average total Quality of Life Index in a range of (0-100) was 56\%(22).In another study conducted in the Karaj city, the results showed the Quality of Life of women was at a moderate 
level(23).Moreover, in the Golami study, Quality of Life was worse significantly in women in physical domain(24).

Another study showed that the quality of life of Iranians is lower than that of other countries, especially on environmental issues (25).A study in Slovakia found that there were statistically significant differences between the quality of life and regions, in terms of economic, social, and environmental factors (26). Therefore, Quality of Life is determined by the different conditions in which people's lives are sustained(27).

In brief, the Quality of Life from the perspective of people in different situations is different and goes back to the individual's satisfaction with her life and with factors such as age, culture, gender, education, class status and social environment(28), which could explain the differences in the results of various studies.

Contrary to our expectations in this study there was no significant relationship between age and QoL index. Based on the results of Rimaz et al, and Bayat et al, there was a statistical relationship between age and the overall quality index in women (29).In Golmakani's study, it was shown that as people got older, their Quality of Life decreased(30).Aging increases the probability of developing mental and physical chronic diseases significantly (6).The loss of spouse, or the family and social level isolation, especially for those at an older age, cause loneliness. Living a lonely life reduces the quality of life, as loneliness may sometimes results in anxiety and depression(31).The results of the above studies are inconsistent with those of the current study. Perhaps one of the reasons for this disagreement is the lower number of women here who fell into the older age groups.

Further analysis of results in this study have shown a statistically significant relationship between education level and Quality of Life in these participants. Education level can play a positive and constructive role in every person's life. Knowledge learning through scientific learning in various fields and the acquisition of more knowledge has the property that prevents a person from committing inappropriate behaviors and determines the position of the woman in their society. In addition, improving the educational attainment of women affected their skills and increased their employment opportunities(22).

Today, women are interested in employment in order to show their abilities and increase selfesteem and self-fulfillment. Women's employment status is another factor related to increasing the Quality of Life of women and the comparison of the mean scores in some studies showed that working women have a better quality of life compared to housewives(22),(28),(32). The results of a study in China showed that subjective well-being was affected by socioeconomic status, and the most influential variables in this regard were education, employment and income(33). The results of a study conducted in Tabriz showed that there was no significant difference between the quality of life of working women and housewives(34). Moreover, the results of the research of Ahmadian et al, in Mashhad showed that there was no statistically significant difference between the quality of life of employed and non-employed women, but there was a significant difference between the tolerance status of employed and housewives(35). According to the results of that study, there was no statistically significant difference between the life quality index score of employed women and of housewives too, which is consistent with the results obtained in our study. In explaining the reason, it should be said that a set of factors affects the quality of life of these two groups, which sometimes has a positive effect and sometimes a negative effect. On the other hand, housewives have less problems and worries than working women, and experience less stress, and are more satisfied with their leisure time. 
There was a relationship between the number of children and marital satisfaction of housewives in the Kheri study, which increased the level of marital satisfaction with an increasing number of children. However there was no significant relationship between the number of children and the satisfaction of working women(32). In Golmakany's study, there was no statistically significant relationship between the number of offspring and quality of life(30), which corresponds to the results of this study.

In the study by Solhi et al, the quality of life of female-headed households was moderate, and the lowest mean score is related to the environmental dimension(36). Also, a study conducted in Abadan showed the difference in the quality of life of female-headed households with nonfemale-headed households(37), is in line with the results of the present study.

Overall, quality of life has various physical, psychological and social dimensions that cover a wide range of lives. The findings show that the impact of these dimensions on the quality of life and different people is different. With the entry of married women into the labor market, their former roles change significantly and the role of wife and mother is added to the job role. But not only does women's employment not have a negative impact on their lives, but it must be said that it increases the level of empowerment of women, and in the meantime, if she also has the support of her husband, a better result will be achieved.

\section{Conclusion}

An overview of the results of studies in various disciplines shows that the social sciences examine the quality of life in a broader perspective than health sciences, and the population it studies is more diverse and the content of quality elements of life in this area is substantively wider. Accordingly, quality of life studies in the health sector are more limited in scope. As Ware (1987) noted "jobs, housing, schools, and the neighborhood are not attributes of an individual's health, and they are well outside the purview of the health care system." These characteristics can lead to the study of quality of life towards a more detailed study of this structure. Since most quality-of-life studies are related to health or this index has often been studied in specific groups such as the elderly, patients, and pregnant women, we suggest that for studies on Quality of Life, more attention be paid to the holistic approach, which requires the use of similar scales in this study that address the social components of this concept.

\section{Limitation}

Our study has some limitations that should be considered. First, because of its cross-sectional design, our results should not be interpreted as causal. Future research should study these patterns over time using longitudinal data. Also, it is an observational study and all study subjects volunteered to participate in the questionnaire, though the study sample was of remarkable size, and it was spread out in many geographical areas of the city, this does not necessarily reflect the characteristics of all Iranian women. In this study we investigated only married women and suggest that future studies should also examine the lives of single women. Another limitation of the study was the presence of a covid 19 pandemic at the time of the study, which caused individuals to respond quickly to questions to shorten the response time and increased the likelihood of unrealistic answers.

\section{Ethics declarations}

\section{Ethics approval and consent to participate}

The study was approved by the Research Ethics Committee of Tehran University of Social Welfare and Rehabilitation Sciences (Code: IR.USWR.REC.1398.200) and also was performed under the Declaration of Helsinki and national ethical codes. 
According to the statement, medical research is subject to ethical standards that lead to respect for all human beings and the protection of their health and rights. It is the duty of the researcher to protect the life, health, dignity, honesty, right to self-determination, privacy and confidentiality of personal information.

This study can only follow these standards in some cases where it is relevant. Therefore, efforts were made to promote and maintain the health, well-being and rights of the people who participated in this study. Also, in order to comply with the objectives of this statement, the samples were representative of the study population and the privacy of the participants and the confidentiality of their personal information were assessed.

All participants in this study were sufficiently aware of the objectives, methods, financial resources, any conflict of interest, and institutional dependence of the researcher, anticipated benefits, and potential risks, therefore Informed consent was obtained from all participants. In addition, the researcher explained the potential right to refuse to participate in the study or to withdraw consent to participate at any time without retaliation and the right to be informed of the results of the study if desired. Research on people who are physically or mentally dissatisfied has been dropped.

\section{Consent for publication}

Not Applicable.

\section{Availability of data and materials}

The datasets used and/or analyzed during the current study are available from the corresponding author on reasonable request.

\section{Funding}

This study was a part of the Asiyeh Namazi's PhD thesis that was performed by the support of the Research Deputy of Tehran University of Social Welfare and Rehabilitation Sciences. This research did not receive any specific grant from funding agencies in the public, commercial, or not-for-profit sectors

\section{Competing Interests}

The authors report no competing interest.

\section{Author's contributions}

Contributions to conception and design, acquisition of data: A.N, H R, M M, A S F. Analysis and interpretation of data: A.N., Gh Gh. Drafting the article: A.N. writing — review and editing: A.N, H R., MM, AS F, Gh Gh. All authors have read and agreed to the published version of the manuscript.

\section{Acknowledgements}

The researchers wish to thank the Deputy of Tehran University of Social Welfare and Rehabilitation Sciences, and the women of the Rasht, that participated in this study for their patience and trust in the researchers and all those who helped us in performing this study.

\section{References:}

1. Firozjayan A, Dehghan M. The relationship and impact of life objective quality on the life subjective quality (Case Study: Amol city, Mazandaran province). Socio -Cultural Dev Stud. 2015;3(4):157-84.

2. Koohi F, Nedjat S, Yaseri M, Cheraghi Z. Quality of Life among General Populations of Different Countries in the Past 10 Years, with a Focus on Human Development Index: A Systematic Review and Meta-analysis. Iran J Public Health [Internet]. 2017 
Jan;46(1):12-22. Available from: https://pubmed.ncbi.nlm.nih.gov/28451525

3. Rodrigues J, Chicau Borrego C, Ruivo P, Sobreiro P, Catela D, Amendoeira J, et al. Conceptual Framework for the Research on Quality of Life. Sustainability [Internet]. 2020;12(12). Available from: https://www.mdpi.com/2071-1050/12/12/4911

4. Hosseini Amin N, Seyed Mirzaie M, Adrisi A. Socio-Economic Factors Affecting the Quality of Life of Tehranian Citizens. Soc Welf Q. 2017;17(66):223-54.

5. Fatehi F, Monajemi A, Sadeghi A, Mojtahedzadeh R, Mirzazadeh A. Quality of Life in Medical Students With Internet Addiction. Acta Med Iran. 2016;54(10).

6. Farajzadeh Ms M, Ghanei Gheshlagh PhD R, Sayehmiri PhD K. Health Related Quality of Life in Iranian Elderly Citizens: A Systematic Review and Meta-Analysis. Int J community based Nurs midwifery [Internet]. 2017 Apr;5(2):100-11. Available from: https://pubmed.ncbi.nlm.nih.gov/28409164

7. Cruz JP, Felicilda-Reynaldo RFD, Lam SC, Machuca Contreras FA, John Cecily HS, Papathanasiou I V., et al. Quality of life of nursing students from nine countries: A crosssectional study. Nurse Educ Today. 2018;66.

8. Makovski TT, Schmitz S, Zeegers MP, Stranges S, van den Akker M. Multimorbidity and quality of life: Systematic literature review and meta-analysis. Ageing Res Rev [Internet]. 2019;53:100903. Available from: http://www.sciencedirect.com/science/article/pii/S1568163719300066

9. Sundriyal R, Kumar R. Depression and life satisfaction among married \& unmarried women. Humanit Soc Sci. 2013;16(3):33-6.

10. Yaya S, Ghosh S, Ghose B. Subjective Happiness, Health and Quality of Life and Their Sociocultural Correlates among Younger Population in Malawi. Soc Sci. 2019;8(2):55.

11. Hosseinzadeh A, Ahmadipour T, Mavalizadeh E. A study relation emotion security, social-economy status on quality of life persons (case study: Ahwaz city). J Soc Dev. 2014;9(1):111-34.

12. Openshaw, Kristi P. The relationship between family functioning, family resilience, and quality of life among vocational rehabilitation [Internet]. All Graduate Theses and Dissertations; 2011. Available from: https://digitalcommons.usu.edu/etd/1099

13. Asghari F, Honardoust A. Comparative study between status of women in Iran and Malysia. Women Dev Polit. 2014;12(1):75-92.

14. Weber M, Harzer C, Scott Huebner E, Hills KJ. Chapter 5 - Measures of Life Satisfaction Across the Lifespan. In: Boyle GJ, Saklofske DH, Matthews GBT-M of P and SPC, editors. San Diego: Academic Press; 2015. p. 101-30. Available from: https://www.sciencedirect.com/science/article/pii/B978012386915900005X

15. Amati V, Meggiolaro S, Rivellini G, Zaccarin S. Social relations and life satisfaction: the role of friends. Genus [Internet]. 2018/05/04. 2018;74(1):7. Available from: https://pubmed.ncbi.nlm.nih.gov/29755134

16. Malik M, Munir N, Ghani MU, Ahmad N. Domestic violence and its relationship with depression, anxiety and quality of life: A hidden dilemma of Pakistani women. Pakistan J Med Sci [Internet]. 2021;37(1):191-4. Available from: https://pubmed.ncbi.nlm.nih.gov/33437275

17. Bright K, Dube L, Hayden KA, Gordon JL. Effectiveness of psychological interventions on mental health, quality of life and relationship satisfaction for individuals and/or couples undergoing fertility treatment: a systematic review and meta-analysis protocol. BMJ Open [Internet]. 2020 Jul 1;10(7):e036030. Available from: http://bmjopen.bmj.com/content/10/7/e036030.abstract

18. Theofilou P. Quality of Life: Definition and Measurement. Eur J Psychol. 2013 Feb 28;9:150-62.

19. Rafiei N, Sharifian Sani M, Rafiey H, Behnampour N, Foroozesh K. Reliability and 
Validity of Persian Version of Quality of Life Index. J Maz Univ Med Sci [Internet]. 2014;24(116):75-83. Available from: http://jmums.mazums.ac.ir/article-1-4273en.html

20. Ferrans C, Powers M. Quality of life index: development and psychometric properties. ANS Adv Nurs Sci. 1985;8(1):15-24.

21. Kimura M, Silva JV da. Índice de qualidade de vida de Ferrans e Powers. Rev da Esc Enferm da USP [Internet]. 2009 Dec [cited 2020 Feb 26];43(spe):1098-104. Available from: $\quad$ http://www.scielo.br/scielo.php?script=sci_arttext\&pid=S0080$62342009000500014 \& \operatorname{lng}=\mathrm{pt} \& \operatorname{lng}=\mathrm{pt}$

22. Mirzaei H, Aghayari T, Katebi M. A Study on Life Quality among Married Women in Family Institution. Sociol Soc Institutions [Internet]. 2014;1(3):71-93. Available from: http://ssi.journals.umz.ac.ir/article_973.html

23. Amiri S, Hajfiroozabadi M, Bahrami Babaheidari T, Sadati L. Survey of quality of life and influencing factors in Alborz university of medical sciences staff. Alborz Univ Med J. 2014;3(1):18-22.

24. Gholami A, Borji J, Chenarani R, Bahavar A, Zareie E. A survey on Quality of Life in Women Referred to Health Centers of Neyshabur-2012. J Sabzevar Univ Med Sci [Internet]. 2015;22(5):732-9. Available from: http://jsums.sinaweb.net/article_750.html

25. Nedjat S, Holakouie Naieni K, Mohammad K, Majdzadeh R, Montazeri A. Quality of life among an Iranian general population sample using the World Health Organization's quality of life instrument (WHOQOL-BREF). Int $\mathrm{J}$ Public Health [Internet]. 2011;56(1):55-61. Available from: https://doi.org/10.1007/s00038-010-0174-Z

26. Oláh J, Hajduová Z, Lacko R, Andrejovský P. Quality of Life Regional Differences: Case of Self-Governing Regions of Slovakia. Vol. 12, Sustainability . 2020.

27. Nowak P. Regional variety in quality of life in Poland. Oeconomia Copernicana. 2018;9(3):381-401.

28. Kermansaravi F, Montazeri A, Bayat B. Quality of life in employed and housewife women: a comparative study. Payesh(health Monit. 2012;11(1):111-6.

29. Rimaz SH, Dastoorpoor M, Vesali Azar Shorbeyani S, Saiepour N, Beigi Z, Nedjat S. The Survey of Quality of Life and its Related Factors in Female-headed Households Supported by Tehran Municipality, Ddistrict 9. irje [Internet]. 2014 Sep 1;10(2):48-55. Available from: http://irje.tums.ac.ir/article-1-5239-fa.html

30. Golmakany A, Shariati Sarcheshmeh M, Marouzi P, Rezaie Sani T. Body Mass Index and its relation to menopausal women's quality of life. gums-hnmj [Internet]. $2016 \mathrm{Apr}$ 1;26(1):48-55. Available from: http://hnmj.gums.ac.ir/article-1-625-en.html

31. Alam MZ. Women outweighed men at life expectancy in Bangladesh: does it mean a better quality of life? Heliyon. 2021;7(7):e07618.

32. Khezri SK, Arjmand Siahpoush E. The Comparison of Marital Satisfaction Level of Working and Householder Women and affecting Factors on Them in Izeh City. J Iran Soc Dev Stud [Internet]. 2014;6(4):97-105. Available from: https://jisds.srbiau.ac.ir/article_6805.html

33. Sun S, Chen J, Johannesson M, Kind P, Burström K. Subjective well-being and its association with subjective health status, age, sex, region, and socio-economic characteristics in a Chinese population study. J Happiness Stud. 2016;17(2):833-73.

34. Fardi Tabrizi Z, Ansari Nejad N, Isfahani Khaleghi A. Comparison of quality of life in working and housewives of Alborz province. In: The Second International Congress on Community Empowerment in the Field of Counseling, Family and Islamic Education. Tehran: https://civilica.com/doc/679059/; 2016.

35. Adel Ahmadian F, Rajaei A. Comparison of quality of life and tolerance of working women and housewives. In: National Conference on New Ideas in Psychology and 
Educational Sciences with Emphasis on Recent Scientific Research. Tehran: https://civilica.com/doc/859236/; 2018. p. 1-8.

36. Solhi M, Hamedan M, Salehi M. Relationship between quality of life of women-headed households and some related factors in Iran. Glob J Heal Sci. 2016;8(10):56241.

37. Isari S. Comparison of emotion control and quality of life in women heads of households and non-heads of households in Abadan. In: The Second National Conference on Psychology and Educational Sciences. shirvan: https://civilica.com/doc/907515/; 2019.

Table 1 - The mean scores of quality-of-life indexes and its domains in Rasht women $(\mathrm{n}=784)$

\begin{tabular}{|l|c|c|c|c|}
\hline $\begin{array}{l}\text { Dimensions of quality-of- } \\
\text { life index }\end{array}$ & $\begin{array}{l}\text { Mean (standard } \\
\text { deviation) }\end{array}$ & Min-score & Max-score & $\begin{array}{l}\text { 95\% Confidence } \\
\text { interval }\end{array}$ \\
\hline Health and function & $21.28(4.53)$ & 7 & 30 & $20.96-21.59$ \\
\hline Psychology / Spirituality & $21.81(5 / 51)$ & 0 & 30 & $21.43-22.20$ \\
\hline Social / Economic & $19 / 94(3 / 99)$ & 4 & 28 & $19.70-20.34$ \\
\hline Family & $23 / 47(4 / 95)$ & 5 & 30 & $23.12-23.82$ \\
\hline Total quality of life index & $21 / 39(4.10)$ & 7 & 30 & $21.12-21.71$ \\
\hline
\end{tabular}

Table 2 - mean (SD) of QLI according to the independent variables of women $(n=784)$

\begin{tabular}{|c|c|c|c|c|c|}
\hline \multirow{2}{*}{ variable } & \multicolumn{2}{|c|}{ Study population } & \multicolumn{2}{|c|}{$\begin{array}{l}\text { Quality of life index } \\
\text { scores }\end{array}$} & \multirow{2}{*}{ P-value } \\
\hline & $\mathrm{N}$ & $\%$ & Mean & $\begin{array}{l}\text { standard } \\
\text { deviation }\end{array}$ & \\
\hline \multicolumn{5}{|l|}{ Age category } & \multirow{5}{*}{0.49} \\
\hline $30-39$ & 372 & 47.4 & 21.60 & 0.47 & \\
\hline $40-49$ & 233 & 29.7 & 21.26 & 3.94 & \\
\hline $50-59$ & 132 & 16.8 & 21.06 & 4.18 & \\
\hline $60 \leq$ & 47 & 6 & 21.80 & 3.50 & \\
\hline \multicolumn{5}{|l|}{ Education status } & \multirow{5}{*}{$0.03 *$} \\
\hline $\begin{array}{l}\text { Non formal } \\
\text { education }\end{array}$ & 0 & 0 & 0 & 0 & \\
\hline Under diploma & 48 & 6.1 & 20.30 & 4.52 & \\
\hline $\begin{array}{c}\text { Diploma and } \\
\text { Associate Degree }\end{array}$ & 263 & 33.5 & 21.85 & 4.13 & \\
\hline $\begin{array}{l}\text { Bachelor's degree } \\
\text { and higher }\end{array}$ & 473 & 60.3 & 21.29 & 4.20 & \\
\hline \multicolumn{5}{|l|}{ Residence of birth } & \multirow{3}{*}{0.34} \\
\hline Rural & 208 & 26.5 & 21.65 & 4.05 & \\
\hline Urban & 576 & 73.5 & 21.33 & 4.27 & \\
\hline \multicolumn{5}{|l|}{ occupation status } & \multirow{3}{*}{0.87} \\
\hline Employed & 528 & 67.3 & 21.40 & 4.10 & \\
\hline housewife & 256 & 32.7 & 21.45 & 4.43 & \\
\hline
\end{tabular}




\begin{tabular}{|c|c|c|c|c|c|}
\hline \multicolumn{5}{|c|}{ Type of employment } & \multirow{3}{*}{0.96} \\
\hline public & 235 & 44.5 & 21.07 & 3.99 & \\
\hline Private & 293 & 55.5 & 21.67 & 4.18 & \\
\hline \multicolumn{5}{|c|}{ Head of household } & \multirow{3}{*}{$0.008^{\oplus \circledast}$} \\
\hline Woman & 66 & 8.4 & 21.27 & 3.27 & \\
\hline Man & 718 & 91.6 & 21.43 & 4.29 & \\
\hline
\end{tabular}

$* p<0.05$

Table 3. Linear regression analysis by considering QOLI as a dependent variable

\begin{tabular}{|l|c|c|c|c|c|}
\hline \multicolumn{1}{|c|}{ factors } & $\mathrm{B}$ & $\mathrm{SE}$ & $\beta$ & $\mathrm{t}$ & $\mathrm{P}$ \\
\hline constant & 21.811 & 1.495 & & 14.589 & .000 \\
\hline Age & -.102 & .067 & -.224 & -1.515 & .130 \\
\hline Age of marriage & .100 & .069 & .128 & 1.448 & .148 \\
\hline Birth place & -.438 & .346 & -.046 & -1.267 & .205 \\
\hline Number of children & .065 & .186 & .017 & .347 & .729 \\
\hline Duration of marriage & .073 & .065 & .194 & 1.121 & .263 \\
\hline Family income & .228 & .163 & .052 & 1.396 & .163 \\
\hline Residential area & -.081 & .112 & -.027 & -.727 & .467 \\
\hline
\end{tabular}

